\title{
Disulfide Engineered Lipase to Enhance the Catalytic Activity: A Structure-Based Approach on BTL2
}

\author{
César A. Godoy ${ }^{1, *} \mathbb{D}$, Javier Klett ${ }^{2} \mathbb{D}$, Bruno Di Geronimo ${ }^{2}$, Juan A. Hermoso ${ }^{3}$,
} José M. Guisán ${ }^{4}\left(\mathbb{D}\right.$ and César Carrasco-López ${ }^{5, *}$

1 Departamento de Química (LIBB), Grupo de Investigación en Ingeniería de los Procesos Agroalimentarios y Biotecnológicos (GIPAB), Universidad del Valle, C.P. 76001 Cali, Colombia

2 Experimental Therapeutics Programme, Spanish National Cancer Research Centre (CNIO), C/Melchor Fernández Almagro 3, E-28029 Madrid, Spain; jklett@cnio.es (J.K.); bdigeronimo@ext.cnio.es (B.D.G.)

3 Department of Crystallography and Structural Biology, Institute of Physical Chemistry "Rocasolano" (IQFR-CSIC), E_28006 Madrid, Spain; xjuan@iqfr.csic.es

4 Departamento de Biocatálisis. Instituto de Catálisis. CSIC. Campus UAM. Cantoblanco. C.P. 28049 Madrid, Spain; jmguisan@icp.csic.es

5 Department of Chemical and Biological Engineering, Hoyt Laboratory, Princeton University, Princeton, NJ 08544, USA

* Correspondence: cesar.godoy@correounivalle.edu.co (C.A.G.); cesarc@princeton.edu (C.C.-L.); Tel.: +57-2-3212100 (ext. 118) (C.A.G.); +1-609-2580542 (C.C.-L.)

Received: 15 August 2019; Accepted: 23 September 2019; Published: 23 October 2019

\begin{abstract}
Enhancement, control, and tuning of hydrolytic activity and specificity of lipases are major goals for the industry. Thermoalkaliphilic lipases from the I.5 family, with their native advantages such as high thermostability and tolerance to alkaline $\mathrm{pHs}$, are a target for biotechnological applications. Although several strategies have been applied to increase lipases activity, the enhancement through protein engineering without compromising other capabilities is still elusive. Lipases from the I.5 family suffer a unique and delicate double lid restructuration to transition from a closed and inactive state to their open and enzymatically active conformation. In order to increase the activity of the wild type Geobacillus thermocatenulatus lipase 2 (BTL2) we rationally designed, based on its tridimensional structure, a mutant ( $c$ BTL2) capable of forming a disulfide bond to lock the open state. $c c B T L 2$ was generated replacing A191 and F206 to cysteine residues while both wild type C64 and C295 were mutated to serine. A covalently immobilized $c$ BTL2 showed a 3.5-fold increment in esterase activity with $0.1 \%$ Triton X-100 (2336 IU mg ${ }^{-1}$ ) and up to 6.0 -fold higher with $0.01 \%$ CTAB (778 IU mg ${ }^{-1}$ ), both in the presence of oxidizing sulfhydryl agents, when compared to BTL2. The remarkable and industrially desired features of BTL2 such as optimal alkaliphilic $\mathrm{pH}$ and high thermal stability were not affected. The designed disulfide bond also conferred reversibility to the enhancement, as the increment on activity observed for $c c B T L 2$ was controlled by redox pretreatments. MD simulations suggested that the most stable conformation for $c$ BTL2 (with the disulfide bond formed) was, as we predicted, similar to the open and active conformation of this lipase.
\end{abstract}

Keywords: thermoalkaliphilic lipase; engineered lipase; engineered disulfide bond; interfacial activation; lipases activity enhancement

\section{Introduction}

Lipases (triacylglycerol acyl hydrolases, E.C. 3.1.1.3) are one of the most widely used enzymes in the industry due to their stability, broad substrate specificity, high selectivity, and advantageous promiscuity in some cases [1-3]. The cleaning industry has one of the highest demands for lipases, as alkaline lipases are part of the enzymatic additives intended to increase detergent efficiency and 
sustainability. The improvement of lipase activity and stability in the presence of detergents is a major goal and recurrent topic in this industry $[4,5]$. Lipases often are in a thermodynamic equilibrium between closed and open conformations, the latter being the enzymatically active state, which is found in the presence of water-oil interfaces, substrate analogs, and micelles [6-8]. Transition from closed to open conformation requires the movement and sometimes the structural rearrangement of a helical lid that hinders the active site [6-8]. Several strategies have been developed to increase lipase enzymatic activity, including immobilization on hydrophobic supports, chemical modification, site-directed mutagenesis, and medium engineering (presence of additives as detergents or organic solvents) or the use of Combi-lipases for the transformation of natural triglycerides. In general, these approaches are designed to decrease steric hindrance in the access of the substrate into the enzyme active cleft [9-13]. The introduction of disulfide bonds represents another strategy to modulate the enzymatic properties of lipases. The insertion of cysteine residues at a distance to form a disulfide bond in the core of lipases from Rhizomucor miehei and Yarrowia lipolytica, or in the lid hinge region of the Rhizopus chinensis lipase increased their thermostability and for the latter, also altered the length specificity of the acyl chains that this enzyme is capable to bind and hydrolyze [14-16]. While there are bioinformatic tools to facilitate the design and application of such strategy [17], the rational design and implementation of disulfide bonds to control and increase the hydrolytic activity of lipases, without compromising other enzyme features, remains elusive.

The lipase 2 of Geobacillus thermocatenulatus (BTL2) is a thermoalkaliphilic enzyme (part of the I.5 family of lipases) whose interesting properties, such as high thermal stability, high substrate selectivity, and tolerance to alkaline $\mathrm{pHs}$, have been explored for biotechnological application [18]. The structure of BTL2 defined the unique conformational changes that the I.5 family of lipases suffer upon activation, including a characteristic double lid that controls the transition between the open (active) and closed (inactive) conformations [7,18]. This double lid consists in a main lid (residues 169 to 200) that changes its secondary structure during the process of interfacial activation revealing the active site groove (open conformation), and a secondary lid (residues 217 to 234) that plays the role of other common lipase lids, and that in BTL2 structurally supports the main lid and helps stabilizing the enzymatically active state [5]. Several strategies have been applied to enhance its catalytic properties, including chemical modifications with small molecules, polymers, peptides, and/or through molecular biology tools [19-23]. Thus, its enzymatic activity is substantially impacted when the double lid of BTL2 is modified $[13,19,23,24]$.

Based on the known open conformation of BTL2 [7] and a model of its closed state using the homologous (95\% identity) L1 from Geobacillus stearothermophilus (also part of the I.5 family) as a template [25], we designed a quadruple mutant (A191C, F206C, C64S, and C295S) (called henceforth ccBTL2 in this study), containing only two cysteine residues (Figure S1). These cysteine residues are secluded and structurally far away in the closed conformation, but in proximity and able to interact and form a disulfide bond as they approach in the open state (Figure 1). This disulfide bond was designed to act as a physical restraint that would keep the lipase in its active conformation. The previously reported free cysteine BTL2 mutant (C64S, C295S) (based on the pT1BTL2 plasmid [26]) was used to produce $c c$ BTL2 by including the mutations A191C and F206C [27]. Since soluble lipases are prone to form aggregates, CNBr-Sepharose ${ }^{\circledR}$ conjugated derivatives of ccBTL2 and BTL2 were made to avoid artifacts resulting from intermolecular interaction during the characterizations [28-30]. The effect of the presence of surfactants and thiol-disulfide redox pretreatments, among others, on the activity of insoluble preparations of BTL2 and ccBTL2, were determined. The activation mechanism of the mutant and wild type enzyme was analyzed by targeted molecular dynamics (TMD) to structurally enlighten the observed behavior [31]. 
(a)

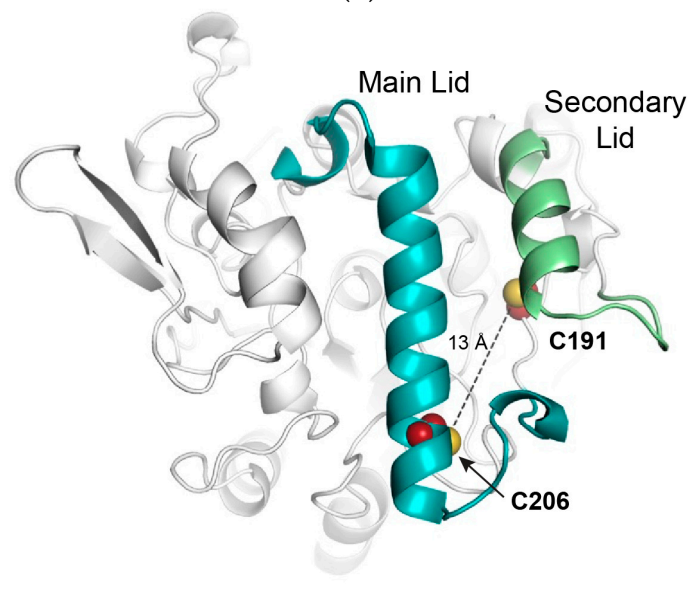

Closed (b)

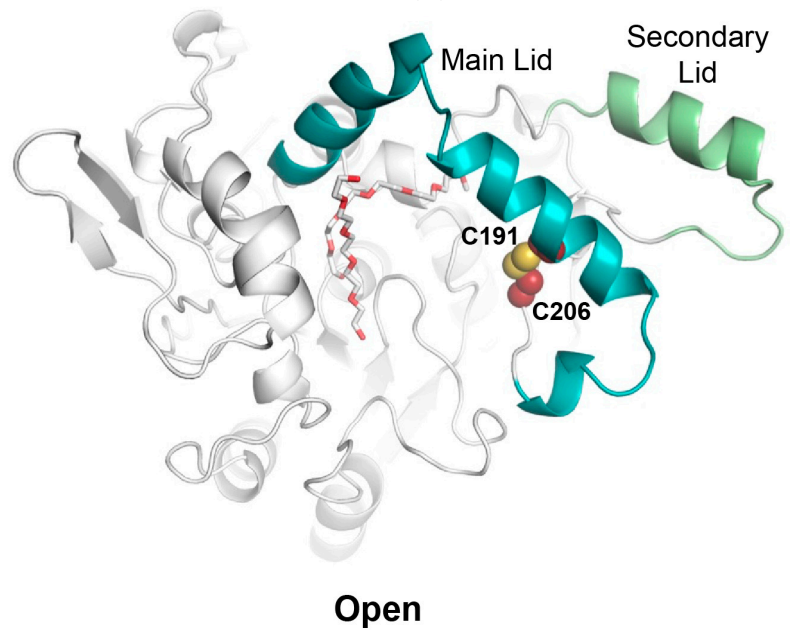

Figure 1. Design and modeled disulfide bond in co-crystallized wild type Geobacillus thermocatenulatus lipase 2 (ccBTL2). (a) Model of the closed conformation of ccBTL2 (using wild type Geobacillus stearothermophilus lipase 1 (BSL1) as template). The residues C206 and C191 (red and yellow spheres) are $13 \AA$ away from each other (dotted line). The main and secondary lids are labeled (blue and green cartoons respectively). (b) Model of the open conformation of $c$ BTL2 based on the crystallographic structure of BTL2 in complex with Triton X-100 moieties (red and white sticks). In this conformation the cysteine residues are within an interaction distance to form a disulfide bond keeping ccBTL2 in an active conformation.

\section{Results and Discussion}

\subsection{Design of An Engineered BTL2 Mutant (ccBTL2) to Lock the Open Conformation}

According to the open structure of BTL2 co-crystallized with two molecules of Triton X-100 (PDB code: 2W22) and the closed conformation of a highly homologous Geobacillus stearothermophilus L1 (BSL1) (sharing 95\% identity, PDB code: 1JI3), the residues F206 and A191 are reasonably far from each other $(13 \AA)$ and structurally secluded in the inactive (closed) state but nearby ( $3.5 \AA$ ) and partially exposed in the active (open) conformation (Figure 1). The residue F206, at the core of the protein, remains relatively immobile during the close-to-open transition and helps anchoring the conformation of the secondary lid in the closed state. On the other hand, residue A191, belonging to the $\alpha$-helix that covers the active site pocket (and part of the main lid), suffers a considerable displacement (around $20 \AA$ ) between active and inactive conformations. Thus, we hypothesized that replacement of these residues by cysteine would, under certain conditions (e.g., presence of Triton X-100 and oxidizing agents), induce the formation of a disulfide bond (C191-C206) in the open conformation, that could stabilize and lock the active state of the enzyme.

To avoid undesirable disulfide bond formation between wild type cysteine residues, C64, and C295 were previously mutated to serines obtaining the pT1øBTL2 plasmid we used as template [27]. We modeled the closed conformation of the designed mutant ccBTL2 (Figure 1) using the automated homology modeling program (ESyPred3D web server 1.0, www.fundp.ac.be/sciences/biologie/urbm/ bioinfo/esypred/) [32], and with the Geobacillus stearothermophilus L1 lipase BSL1 (from the same I.5 family) in the closed conformation as template (PDB code: 1KU0). Sharing 95\% identity, their tridimensional structure was basically identical having only few substitutions. The ccBTL2 open conformation was obtained by manually modifying the BTL2 open structure (2W22) to include the F206C and A191C mutations, followed by an energy minimization. According to these models, and as expected, the restructuration of the lids brings together the residues C191-C206 that would facilitate the formation of the disulfide bond in an enzymatically active conformation (open). The structural 
alignment of BTL2 and ccBTL2 models showed that no major structural changes are introduced by the F206C and A191C mutations (RMSD = $0.101 \AA$ ).

\section{2. ccBTL2 Conserved Similar Expression and Optimal Properties}

As previously reported for other BTL2 mutants [21,22], the ccBTL2 recombinant expression was similar to that of BTL2 enzyme (7763 versus 7502 IU of $p$-NPB esterase activity/g wet cells, respectively) using the same expression system [26,27]. A SDS-PAGE with samples of both purified ccBTL2 and BTL2 showed a single $\sim 43 \mathrm{kDa}$ band for each enzyme (Figure S2). The purified $c c B T L 2$ mutant, without redox pretreatment, had a specific activity $(630 \mathrm{IU} / \mathrm{mg})$ similar to that of the BTL2 (660 IU/mg) (Table 1).

Table 1. Properties of BTL2 and ccBTL2 CNBr-Sepharose ${ }^{\circledR}$ derivatives with $5 \mathrm{IU}$ and $0.013 \mathrm{mg}$ of protein/g.

\begin{tabular}{|c|c|c|c|c|c|}
\hline Enzyme & $\begin{array}{l}\text { Specific } p \text {-NPB } \\
\text { Esterase Activity } \\
(\mathrm{IU} / \mathrm{mg})^{\mathrm{a}}\end{array}$ & $\begin{array}{c}\text { Activity } \\
\text { Recovery (\%) }\end{array}$ & Optimal $\mathrm{pH}^{\mathrm{c}}$ & $\begin{array}{c}\text { Optimal } \\
\text { Temperature } \\
\left({ }^{\circ} \mathrm{C}\right)^{d}\end{array}$ & $\begin{array}{c}t_{1 / 2} \text { at } 75^{\circ} \mathrm{C} \\
\quad(\min )^{d}\end{array}$ \\
\hline BTL2 & $660 \pm 21$ & $65 \pm 2.3$ & $8.5-9.5$ & $64 \pm 3.1$ & $28 \pm 1.3$ \\
\hline ccBTL2 & $630 \pm 17$ & $67 \pm 3.1$ & $8.5-9.5$ & $66 \pm 2.3$ & $30 \pm 1.1$ \\
\hline
\end{tabular}

${ }^{\text {a }}$ At $\mathrm{pH} 7.00$ in $25 \mathrm{mM}$ sodium phosphate buffer at $25^{\circ} \mathrm{C}$ with $0.40 \mathrm{mM}$ of $p$-nitrophenyl butyrate $(p-\mathrm{NPB})$ for soluble enzymes. ${ }^{\mathrm{b}}$ In regard to the correspondent control suspension of free enzyme and blocked CNBr-support (Cyanogen bromide-Sepharose ${ }^{\circledR}$ ) [20]. ${ }^{\mathrm{c}}$ With $0.40 \mathrm{mM}$ of $p$-NPB at $25^{\circ} \mathrm{C}$ in sodium borate buffer. ${ }^{d}$ In presence of $0.40 \mathrm{mM}$ of $p$-NPB at pH 7.00 in $25 \mathrm{mM}$ sodium phosphate buffer.

Immobilization of the enzymes onto CNBr-Sepharose ${ }^{\circledR}$ resin showed similar activity recovery for both BTL2 (65\%) and ccBTL2 (67\%). No significant differences were observed for the optimal activity in terms of thermal stability $\left(\right.$ at $75^{\circ} \mathrm{C}$ ) and $\mathrm{pH}(7.0)$. Table 1 resumes similar overall properties of both enzymes and their immobilized derivatives and shows that the commonly desirable properties of the thermoalkaliphilic I.5 family were not affected in our engineered ccBTL2.

\subsection{A Tunable Formation of the Disulfide Bond in ccBTL2}

As ccBTL2 was thermodynamically and biochemically comparable to BTL2, we then characterized the effect of redox pretreatments to control the formation of the disulfide bond in $c c B T L 2$ and its activity. The enzymes were immobilized $\mathrm{CNBr}$-Sepharose ${ }^{\circledR}$ resin to reduce artifacts from protein-protein interactions (e.g., through their free $\beta$-thiol groups). To follow the formation of the disulfide bond we used 4-PDS to monitor the oxidation state of the cysteine residues. This compound interacts with the reduced state of the $\mathrm{S}$ groups (-SH) releasing 4-pyridinethiol that after tautomerization absorbs at $324 \mathrm{~nm}$ [33]. The 4-PDS was added after no redox treatment, or after either a reducing treatment with DTT (or glutathione) or oxidizing treatment with $\mathrm{Cu}^{2+}$ (or oxidized glutathione). Increment in absorbance at $324 \mathrm{~nm}$ indicates the presence of $-\mathrm{SH}$ groups and therefore no disulfide bond formed. The untreated $c c B T L 2$ derivative showed lower $\mathrm{A}_{324 \mathrm{~nm}}$ values $(\sim 0)$ than those of BTL2, suggesting that $\beta$-thiol groups were already oxidized and the disulfide bond formed in the purified protein. During the extraction and purification of $c c B T L 2$, the enzyme was exposed to both detergents and oxygen (exposed to air) that could trigger the adoption of the open conformation and oxidize the cysteine residues, respectively, favoring the formation of the disulfide bond when the residues were in close proximity. In addition, it has been reported that disulfide bonds can be obtained "spontaneously" when natural or synthetic peptides are dissolved in aqueous medium (distinctin, CXCR4 inhibitors) and exposed to air as long as they previously achieve the correct native conformation [34]. Disulfide bond formation can also be promoted by $\mathrm{Zn}(\mathrm{II}), \mathrm{Fe}(\mathrm{II}), \mathrm{Cd}(\mathrm{II})$ or Sulfur when present even as traces in the culture media, buffers or in agarose based materials as those used in our study [35]. Our results clearly indicate a formation of the disulfide bridge C206-C191 in the purified ccBTL2 previous to any redox treatment, which we believe was very likely promoted after extraction and purification. It is 
noteworthy that perhaps no pretreatment would be necessary for eventual industrial applications of such BTL2 mutant.

Next, we wanted to control and test the reversibility of the disulfide bond formation. We then used DTT as reducing agent and $\mathrm{Cu}^{2+}$ as catalyst for oxidation, which were more effective than glutathione and oxidized glutathione, respectively. In both cases denaturing conditions during the application of the treatment (using guanidine) increased the effectiveness of pretreatments (Table 2) probably by promoting higher exposition of $\beta$-thiol groups [36]. DTT $(25 \mathrm{mM})$, triggered the highest values of $\mathrm{A}_{324 \mathrm{~nm}}$ for both ccBTL2 and BTL2, suggesting a high degree of free $\beta$-thiol groups ( $\left.>90 \%\right)$ in both immobilized enzymes according to the expected maximum $A_{324 n m}$ value ( 0.74). When the reduced immobilized enzymes were then incubated under oxidizing conditions using $\mathrm{Cu}^{2+}, \mathrm{A}_{324 \mathrm{~nm}}$ returned to values close to zero $(<0.1)$, indicating that now the $\beta$-thiol groups were effectively re-oxidized showing a precise degree of control and reversibility of the system. A total of five oxidation-reduction cycles were repeated using $\mathrm{Cu}^{2+}$ and DTT $(200 \mu \mathrm{M}$ and $25 \mathrm{mM}$, respectively). BTL2 had an irreversible oxidation after three cycles with $\mathrm{A}_{324}$ values remaining close to zero. In contrast, $\mathrm{A}_{324}$ values for ccBTL2 were essentially the same after a fifth cycle for either the oxidation step $(\sim 0)$ or reduction step $(\sim 0.7)$ demonstrating a higher tolerance to the redox treatment.

Table 2. 4,4'-dipyridyldisulfide (4-PDS) assay for CNBr-Sepharose ${ }^{\circledR}$ derivatives (6600 IU of p-nitrophenylbutyrate (p-NPB)/g) after $24 \mathrm{~h}$ of different pretreatments.

\begin{tabular}{|c|c|c|c|c|}
\hline \multirow{2}{*}{\multicolumn{3}{|c|}{$\begin{array}{c}\text { Pretreatment in Presence (+) or Absence (-) of } \\
\text { Guanidine } 8 \mathrm{M}\end{array}$}} & \multicolumn{2}{|c|}{$\begin{array}{c}\text { nmol of Equivalent Free Cys Per } \\
\text { mg of Protein a }\end{array}$} \\
\hline & & & BTL2 & ccBTL2 \\
\hline \multirow{2}{*}{\multicolumn{2}{|c|}{ As obtained }} & - & $35.0 \pm 2.26$ & $0.752 \pm 0.62$ \\
\hline & & + & $7.01 \pm 1.25$ & $2.01 \pm 0.02$ \\
\hline \multirow{4}{*}{ Reducing incubation } & & - & $34.8 \pm 4.45$ & $42.0 \pm 1.75$ \\
\hline & 25 mM DTT & + & $42.9 \pm 1.88$ & $44.0 \pm 2.26$ \\
\hline & GSSG $1 \mathrm{mM} /$ & - & $31.4 \pm 2.63$ & $32.4 \pm 1.31$ \\
\hline & GSH 10 mM & + & $34.5 \pm 3.13$ & $38.4 \pm 2.57$ \\
\hline \multirow{4}{*}{ Oxidizing incubation } & $2004 \mathrm{M} \mathrm{C}_{11}^{2+}$ & - & $4.82 \pm 1.38$ & $6.08 \pm 1.32$ \\
\hline & $200 \mu \mathrm{MCu}^{2+}$ & + & $4.51 \pm 1.88$ & $1.00 \pm 0.81$ \\
\hline & GSSG $10 \mathrm{mM} /$ & - & $19.6 \pm 1.13$ & $12.4 \pm 4.40$ \\
\hline & GSH 1 mM & + & $2.63 \pm 0.69$ & $7.02 \pm 2.00$ \\
\hline
\end{tabular}

a Absorbance of the supernatant after suspending the correspondent pretreated derivative (with 4-PDS $1 \mathrm{mM}$ at $\mathrm{pH}$ 7.50 under denaturing conditions ( $8 \mathrm{M}$ guanidine) at a final volume of $5 \mathrm{~mL}$. Blank was the supernatant resulting from the same experiment but using blocked CNBr-Sepharose ${ }^{\circledR}$. GSSG (oxidized glutathione); GSH (reduced glutathione); dithiothreitol (DTT).

\subsection{Activity of the Engineered ccBTL2 Is Enhanced in Presence of Detergent}

\subsubsection{Effect of $\mathrm{Cu}^{2+}$ Pretreatment in Enzymatic Activity in Absence of Detergents}

Immobilized ccBTL2 activity remains unaltered upon incubation with low concentrations of $\mathrm{Cu}^{2+}$ $(20 \mu \mathrm{M})$, even when $\beta$-thiol groups are oxidized (Figure 2), and showed slower inactivation than BTL2 upon incubation with higher concentrations of $\mathrm{Cu}^{2+}(200 \mu \mathrm{M})$ (Figure 2). 


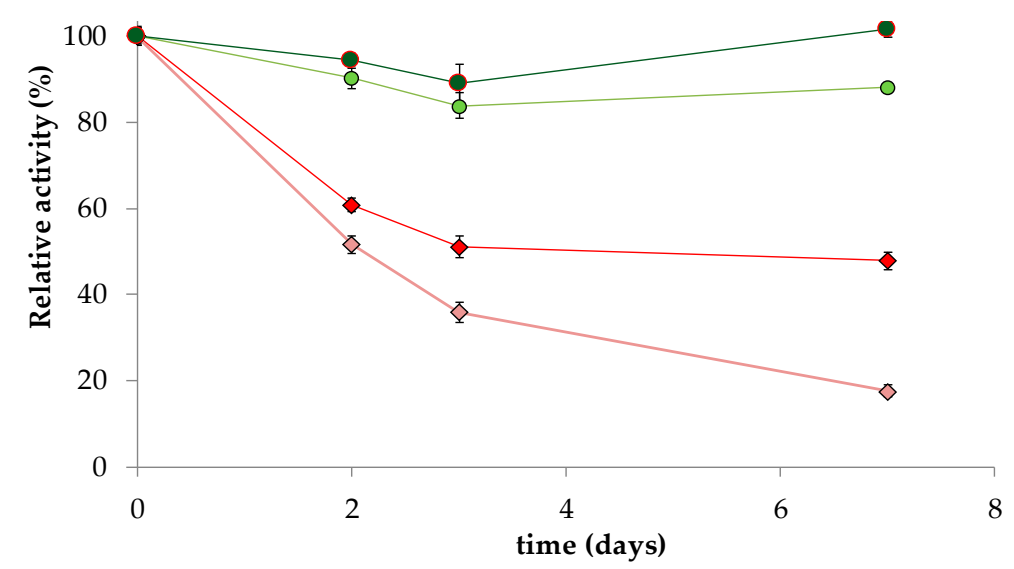

Figure 2. Effect of $20 \mu \mathrm{M} \mathrm{Cu}^{2+}$ (dark green and red) and $200 \mu \mathrm{MCu}^{2+}$ (light green and pink) incubations at $\mathrm{pH} 7.50$ and $30{ }^{\circ} \mathrm{C}$ in presence of $0.1 \%(w / v)$ Triton $\mathrm{X}-100$ on the relative hydrolytic activity of $\mathrm{CNBr}$ derivatives of $c c B T L 2$ (circles) and BTL2 (rhombus). Initial derivative activity was $5 \mathrm{IU}(p$-NPB) and $0.013 \mathrm{mg}$ of $\mathrm{protein} / \mathrm{g}$.

This is consistent with previous findings for free BTL2 and the homolog Geobacillus stearothermophilus lipase 1 (BSL1), both inactivated in the presence of $\mathrm{Ag}^{+}$and $\mathrm{Cu}^{2+}$, which act as catalyzers in the oxidization of $\beta$-thiol groups $[37,38]$. Oxidation of wild type Cys residues can explain the DTT mediated reactivation of immobilized BTL2, which was inactivated after denaturation in guanidine [39]. ccBTL2 was stable and with similar activity after treatment with guanidine, an effect that is probably a consequence of the high stability provided by the disulfide bond being previously formed.

\subsubsection{Hydrolysis of $p$-NPB in Presence of Detergents}

Lipases are key additives for the washing industry [4,5]. Among their applications, optimal concentrations of detergents can improve free or immobilized lipases catalytic activity, most probably by disaggregation of oligomeric forms, stabilization of the active enzyme conformation, and/or facilitating substrate accessibility and dissolution $[40,41]$. Thus, we assessed the effect of detergents on the hydrolytic $p$-NPB activity of immobilized BTL2 and ccBTL2. Both immobilized enzymes without detergent showed a similar $p$-NPB hydrolytic activity (Table 2). However, with $0.01 \%$ CTAB and as obtained after immobilization, ccBTL2 showed enhanced activity $(\sim 200 \%)(w / v)$ while the wild type immobilized enzyme showed an opposite effect, a reduction to 33\%, meaning that ccBTL2 was 6-fold higher increment (Figure 3a; I versus 1). On the other hand, with the addition $0.1 \%(w / v)$ Triton X-100 (Figure 3b; I versus 1) the relative activity increment was again higher for ccBTL2 (605\%) than for BTL2 $(235 \%)$. Is important to note that these results were obtained without using any redox pretreatment, which again indicates a very likely oxidized state of the $c c$ BTL2 as the 4-PDS assay indicated.

Reversibility of the system was tested by the application of sequential oxidation-reductionoxidation cycles while measuring the activity of conjugated lipases at different concentrations of Triton X-100. In Figure $3 b$ (II versus 2) it is shown that the initial oxidizing pretreatment (with $200 \mu \mathrm{M} \mathrm{Cu}^{2+}$ ) did not cause substantial effects on the activity of $c c$ BTL2 (maximum was 611\%) while for the BTL2 the oxidizing treatment causes a general activity decrease. The maximum activation value for BTL2 went from $272 \%$ to $174 \%$ at a concentration of $0.1 \%$ of Triton X-100, implying that ccBTL2 has 3.5 -fold higher activity increment after this pretreatment. The subsequent pretreatment of $c c B T L 2$ derivative at reducing conditions ( $25 \mathrm{mM}$ DTT) caused a loss of relative activity (maximum value went from $605 \%$ to $426 \%$ ) while for the wild type the reducing pretreatment caused a partial recovery from $174 \%$ to $221 \%$ (Figure $3 \mathrm{~b}$ or $3 \mathrm{c}$; III versus 3). The final oxidation pretreatment (Figure 3c; IV versus 4), brings back ccBTL2 to the initial high relative activity values (604\%). At this point, BTL2 showed (in the 
re-oxidation step) evidence of cumulative inactivation (relative activity value was just $112 \%$ ). These results were in agreement with the 4-PDS measurements after the same pretreatments (Table 2).

(a)

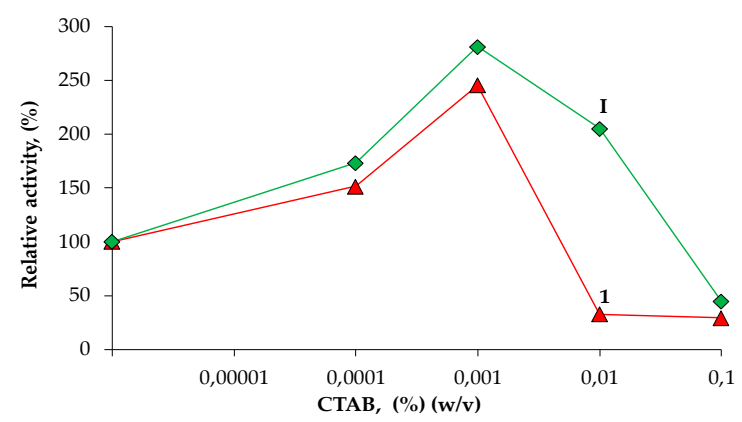

(b)

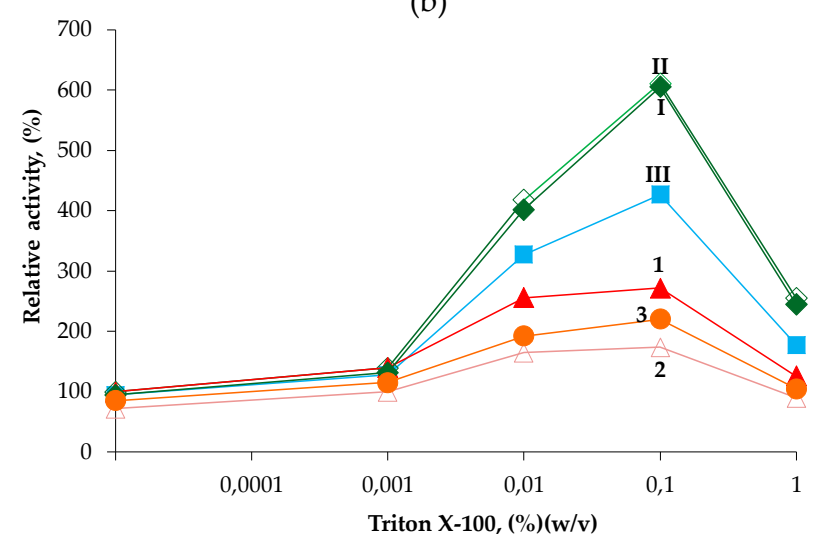

(c)

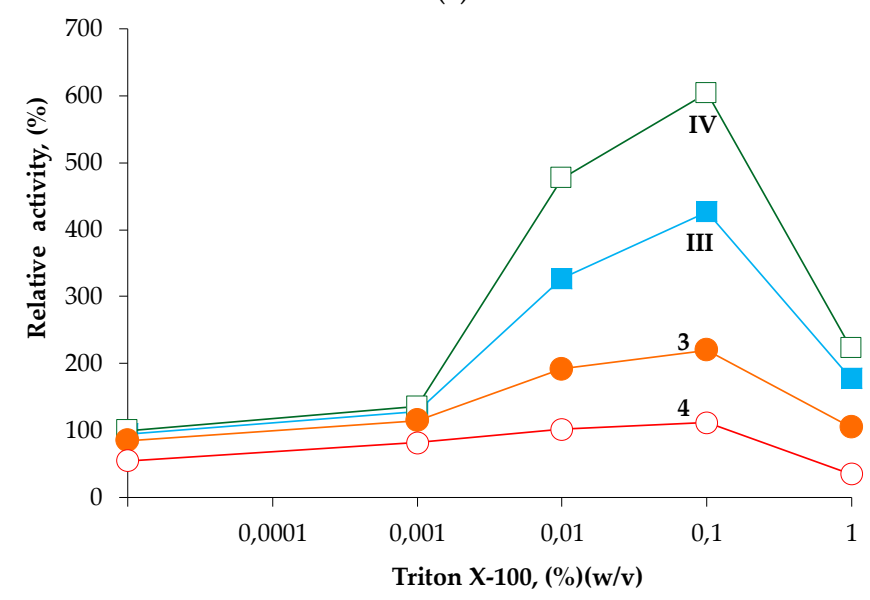

Figure 3. Effect of hexadecyltrimethylammonium bromide (CTAB) (a) on the hydrolytic activity of unmodified CNBr derivatives of BTL2 ("1" or red triangles) and ccBTL2 ("I" or green rhombus). Effect of sequential pretreatments on hydrolytic activity of CNBr lipase derivatives in the presence of Triton $\mathrm{X}-100$. (b): ("I" or green rhombus) ccBTL2 and ("1" or red triangles) BTL2 as obtained; ("II" or open green rhombus) ccBTL2 and ("2" or open pink triangles) BTL2 after incubation with $200 \mu \mathrm{M} \mathrm{Cu}^{2+}$ (first treatment). (b) and (c): ("III" or solid cyan squares) ccBTL2 and ("3" or solid orange circles) BTL2 after posterior incubation with $25 \mathrm{mM}$ DTT (second treatment). (c): ("IV" or open green squares) ccBTL2 and (" 4 " or open red circles) BTL2 re-incubated with $200 \mu \mathrm{M} \mathrm{Cu}^{2+}$ (third treatment). Values are relative to the respective unmodified derivative activity (5 IU $p$-nitrophenyl butyrate ( $p$-NPB) and $0.013 \mathrm{mg}$ of protein/g) in the absence of detergents for $c c$ BTL2. 
All the above confirmed that the designed disulfide bond C191-C206 was already established in the unmodified $c c$ BTL2 after extraction and purification. Both unmodified and re-oxidized $c c$ BTL2 showed the higher relative activity (up to 5.4 times) in the presence of detergents when compared to BTL2. The lack of this engineered disulfide bond may also explain the decreased activity caused by $0.01 \%$ CTAB (Figure 3b) or by $\mathrm{Cu}^{2+}$ oxidative incubation for the BTL2 (Figure 2) for which the oxidation of native cysteine residues has been related before with a less active enzyme form [39]. Our engineered $c c$ BTL2 showed higher activity in the presence of detergents and also higher resistant to the oxidation-reduction cycles while none of the common negative side effects on the activity, in oxidizing conditions, known for the BTL2 [37,38]. This tendency was also seen with other $p$-NP esters of different acyl length chain (Figure S3).

\subsubsection{Transformation of Natural Triglycerides}

Both immobilized (BTL2 and ccBTL2) enzymes were then compared, as obtained from purification or after oxidative or reducing treatments, for the hydrolysis of industrially relevant substrates like sardine oil and in the ethanolysis of palm-olein with ethanol (Table 3).

Table 3. Properties of immobilized BTL2 and ccBTL2 in the transformation of natural glycerides.

\begin{tabular}{|c|c|c|c|c|}
\hline \multirow{2}{*}{ CNBr-Derivative } & \multirow{2}{*}{ Treatment } & \multicolumn{2}{|c|}{ Hydrolysis of Sardine Oil } & \multirow{2}{*}{$\begin{array}{l}\text { Palm Olein Ethyl Esters } \\
\text { Yield at } 72 \mathrm{~h} \mathrm{( \% )}{ }^{\mathrm{c}}\end{array}$} \\
\hline & & $\begin{array}{l}\text { Activity }{ }^{a}(\mu \mathrm{mol} \\
\text { PUFAs/min) }\end{array}$ & $\begin{array}{l}\text { Specificity } \\
\text { (EPA/DHA) }\end{array}$ & \\
\hline \multirow{3}{*}{ BTL2 } & As obtained & $0.86 \pm 0.04$ & $1.9 \pm 0.1$ & $22.1 \pm 1.9$ \\
\hline & $200 \mu \mathrm{M} \mathrm{Cu}^{2+}$ & $0.15 \pm 0.02$ & $2.0 \pm 0.3$ & $<5$ \\
\hline & 25 mM DTT & $0.95 \pm 0.06$ & $1.8 \pm 0.2$ & $30.3 \pm 2.9$ \\
\hline \multirow{3}{*}{ ccBTL2 } & As obtained & $0.96 \pm 0.04$ & $1.6 \pm 0.2$ & $29.5 \pm 1.1$ \\
\hline & $200 \mu \mathrm{M} \mathrm{Cu}^{2+}$ & $0.99 \pm 0.06$ & $1.7 \pm 0.1$ & $34.4 \pm 1.3$ \\
\hline & $25 \mathrm{mM}$ DTT & $0.85 \pm 0.07$ & $1.8 \pm 0.2$ & $25.7 \pm 2.2$ \\
\hline
\end{tabular}

\footnotetext{
a Reaction conditions and analysis were the same as described for the biphasic hydrolysis system [42] (cyclohexane/aqueous buffer at $\mathrm{pH} 7.0$ ) at $25{ }^{\circ} \mathrm{C}$ using highly loaded derivatives (6600 IU $p$-NPB and with $10.7 \mathrm{mg}$ of protein/g); the reactions were followed using reverse phase (RP)-HPLC with an ultraviolet (UV) (215 nm). ${ }^{\mathrm{b}}$ Specificity is defined as the molar eicosapentaenoic acid/docosahexaenoic acid EPA/DHA production rate ratio [42]. ${ }^{\mathrm{c}}$ Palm olein ethanolysis conditions was performed using the one-step solvent-free method (ethanol: oil molar ratio $3: 1$; catalyst at $6 \%$ of the total oil mass) but changing the temperature to $25^{\circ} \mathrm{C}$ and using $96 \%$ ethanol, reaction was followed using FTIR-ATR (attenuated total reflection) [43,44].
}

As seen with $p$-NP esters (Figure S2), the activity of both BTL2 immobilized enzymes against triglycerides was similar, either as obtained after purification or after reductive pretreatments with DTT. However, the oxidative pretreatment was highly detrimental for the BTL2 activity but not for ccBTL2. No significant changes in the EPA/DHA specificity were observed among derivatives regardless of the pretreatment. The low ethyl esters yield values seen in the ethanolysis of palm olein with ethanol were also seen for BTL2 immobilized on glyoxyl supports under mild reaction conditions [43], which in that specific reaction context discards its use as part of more complex catalytic systems as Combi-lipases [44].

\subsection{Exploring ccBTL2 Active Conformation by Molecular Dynamics}

To elucidate the possible conformation(s) adopted by $c c B T L 2$ with the introduction of the mutations A191C and F206C and the formation of the disulfide bond, we generated simulations and models of both BTL2 and $c c$ BTL2.

Since we lacked an initial structure in the closed conformation for BTL2, we generated a reliable homology model (model quality score: Of 0.66) [45]. The model was based on the crystallographic structure of the highly homologous L1 lipase from Bacillus stearothermophilus also belonging to the I.5 family and which, with a $95 \%$ sequence identity, gave us enough confidence on the similitudes of the structural conformations both enzymes adopt [46]. Next, we studied the conformational change between the open (active) and closed (inactive) conformations using targeted molecular 
dynamics (TMD) simulations [47], which determines the transition between conformations by applying standard molecular dynamics (MD) with a modified molecular mechanics force field. The approach employs steering forces dependent on the root mean square distance between the initial state and the target conformation scaled by a force constant. Three TMD simulations were generated from the closed/inactive model towards the open/active conformation found in the crystallographic structure of BTL2 (PDB code: 2W22). Different simulation times and force constants (5, 10 and $50 \mathrm{~ns}$ of simulation time with force constants of $1,0.75$ and 0.5 , respectively) were used. We monitored the distance between the amino acids A191 and F206 and observed that, over the three trajectories generated, only when the structure was near the active form, the distance would be short enough (around $5 \AA$ distance between the alpha carbons) to allow the formation of the engineered disulfide bond on ccBTL2 (Figure 4a-Bottom-left). At this point, we took three different states from the TMD trajectories when the distance was at the required length for the disulfide bond formation and performed the mutations (Figure 4a-top) defining the disulfide bond in silico. Energy minimizations lead to three similar structures that maintained the secondary structure observed in the wild type form (Figure 4a-Bottom-right).

Having a probable conformation for the $c c$ BTL2 mutant form, we then aimed to explore the stability and structural features of this model compared to the wild type open and closed conformations. $200 \mathrm{~ns}$ MD simulations were performed for each of the three molecular structures monitoring the RMSD of the alpha carbons atoms of the whole protein, and also the ones belonging to lids, the main responsible for the conformational changes (Figure 4a) [7]. As expected, we observed larger fluctuations on the open form compared with the closed conformation since the simulation was performed in an aqueous environment and the open conformation tends to fluctuate avoiding the lipophilic environment of the pocket. Nevertheless, ccBTL2 was stable for both overall RMSD and particularly the lids, even with lower fluctuations than the BTL2 in open conformation. We also checked any modifications of the volume of the active site groove (Figure $4 b$ ), defined by the region where the two lipid moieties are found in the crystallographic structure of BTL2 (Figure S4) [7]. Surprisingly, we found that the pocket of the $c c B T L 2$ mutant rather than maintaining the exposed volume of the BTL2 in an open conformation, it increased with an average value of nearly $700 \AA^{3}$ compared to the $450 \AA^{3}$ observed in BTL2, reaching maximum values of nearly $1500 \AA^{3}$. Both, the intermediate state similar to the active conformation reached by $c$ BTL2 and its apparent higher stability could explain the increment in activity while in the presence of detergents.

(a)

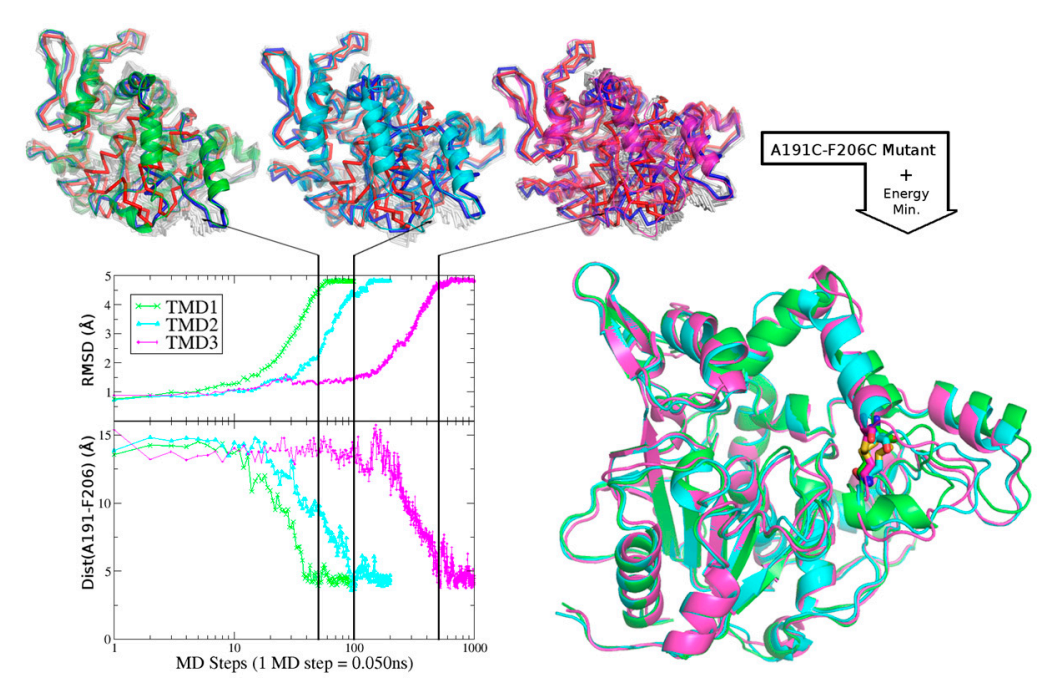

Figure 4. Cont. 
(b)

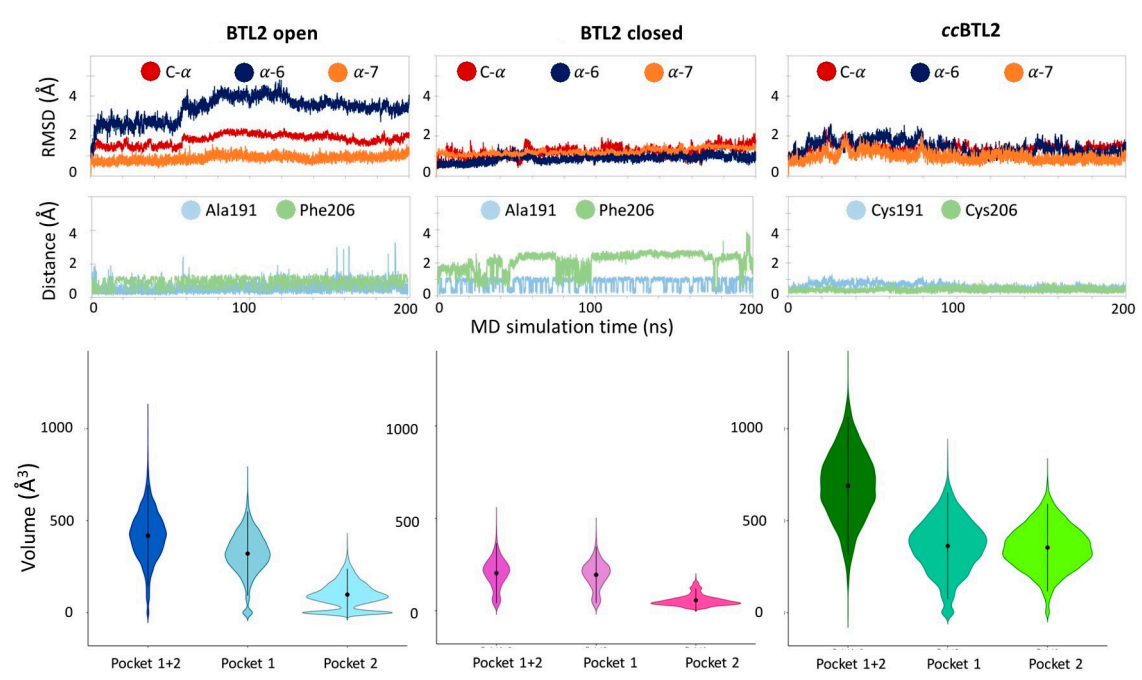

Figure 4. Analysis of the trajectories and conformations during the closed-to-open transition of $c c B T L 2$. (a) (Bottom-left) Plot showing the root-mean-square deviations (RMSD) and distance between A191 and F206, of the structure generated along the targeted molecular dynamics (TMD) from the closed/inactive conformation towards the open/active conformation. (Top) Selected structures among the ensemble of intermediate conformations obtained from the TMD. (Bottom-right) In silico models of the ccBTL2 after energy minimization. (b) Evolution of the RMSD of the entire C- $\alpha$ backbone (red), $\alpha-6$ helix (blue), $\alpha-7$ helix (orange), and in light blue and green the RMSD of the entire amino acid Ala191 and Phe206 and their corresponding mutant during the $200 \mathrm{~ns}$ MD simulation. Violin plots of pocket exposure obtained from the Mdpocket software in $\AA^{3}$; the EGC-404 molecule from the PDB code $2 \mathrm{~W} 22$ has taken as reference for Pocket 1, EGC403 for Pocket 2, and the summary of both for Pocket 1+2. Mean values and standard deviation are also plot (black dots and solid lines).

\section{Materials and Methods}

\subsection{Materials}

The BCA Protein Assay Kit was from Pierce ${ }^{\circledR}$ (Rockford, IL, USA). Cyanogen bromide activated Sepharose ${ }^{\circledR} 4 \mathrm{BCL}(\mathrm{CNBr})$ and butyl Sepharose ${ }^{\circledR}$ CL-4B were purchased from General Electric (Upsala, Sweden). Ethanol, Dimethyl sulfoxide (DMOS), Ethanolamine hydrochloride, hydroxylamine hydrochloride, hexadecyltrimethylammonium bromide (CTAB), Triton X-100, Guanidine hydrochloride, dithiothreitol (DTT), 4,4'-dipyridyldisulfide (4-PDS), oxidized (GSSG) and reduced glutathione (GSH). 1,4-dioxane, $p$-nitrophenyl butyrate ( $p$-NPB) and other $p$-NP esters (acetate, octanoate, dodecanoate and hexadecanoate), $\mathrm{CuCl}_{2} \cdot 5 \mathrm{H}_{2} \mathrm{O}$, ethylenediaminetetraacetic acid (EDTA) and salts for buffering solutions were purchased from Sigma-Aldrich (St. Louis, MO, USA). Palm olein was bought in a local store. The sardine oil was a gift from BTSA, Biotecnologías Aplicadas, S.L. (Madrid, Spain).

\subsection{Site Directed Mutagenesis, Cloning, Expression and Purification of BTL2 Variants}

Site-directed mutagenesis, cloning and experiments were made according to our previous work $[27,48,49]$. The previously constructed øBTL2 mutant pT1C64S, C295SBTL2 plasmid (lacking wild type cysteine codons) [27] was used as template to construct the pT1A191C øBTL2 plasmid by site-directed mutagenesis using the following primers: Forward GCGGTGTTGAAAGCGtgcGCTG TCGCCAGCAAT and reverse ATTGCTGGCGACAGCgcaCGCTTTCAACACCGC. This pT1A191C $ø$ BTL2 plasmid was used then as template to construct the final pT1A191C-F206C øBTL2 plasmid using primers: Forward AGTCAAGTATACGATtgcAAGCTCGACCAATGG and reverse CCATTGG TCGAGCTTgcaATCGTATACTTGACT. Mutations were verified by sequencing. Transformation of 
E. coli BL21(DE3) cells, expression, and purification of BTL2 variants were performed as stated before $[27,48,49]$; all the plasmids mentioned here are based on and derived from the initial pT1-BTL2 vector [26].

\subsection{Protein Determination, Enzymatic Activity Assay, Enzyme Immobilization and Characterization of Derivatives}

Protein determination (BCA pierce method of high sensitivity) and esterase activity against $p$-NPB of soluble or immobilized BTL2 variants at different $\mathrm{pHs}$ and temperature were determined as described before [48]. The $p$-NPB assay in presence of different concentrations of Triton X-100 or CTAB was carried out as previously described [19]. An international unit (IU) of $p$-NPB hydrolysis is defined as the amount of enzyme necessary to hydrolyze one $\mu \mathrm{mol}$ of $p-\mathrm{NPB} / \mathrm{min}$ at $\mathrm{pH} 7.0$ and $25^{\circ} \mathrm{C}$. The preparation of CNBr enzyme derivatives $(5 \mathrm{IU} / \mathrm{g}$ or $6600 \mathrm{IU} / \mathrm{g}$ with a protein content of 0.013 and $10.7 \mathrm{mg}$, respectively), and determination of optimal $\mathrm{pH}$, temperature and stability assays were carried out as reported before [18].

The effect of the acyl chain length of $p$-NP esters on the enzyme activity was determined using a method reported previously [23] with minor modifications: The final substrate concentration was $0.4 \mathrm{mM}$ in $20 \%$ DMSO (80\% aqueous) in $25 \mathrm{mM}$ tris- $\mathrm{HCl}$ buffer $\mathrm{pH} 7.0$ plus $0.01 \%(w / v)$ Triton X-100 at $25^{\circ} \mathrm{C}$. The IU esterase activity is defined as the amount of enzyme necessary to hydrolyze one $\mu \mathrm{mol}$ of $p$-NP ester/min under the described conditions.

\subsection{Assay with 4-PDS for CNBr Derivatives}

The assay was performed as described before $[27,50]$ with modifications: A sample of $\mathrm{CNBr}$ enzyme derivatives $(6600 \mathrm{IU} / \mathrm{g}$ ) was added to obtain the equivalent of $5 \mathrm{mg}$ of protein (according to the BCA method) and suspended in a solution containing $1 \mathrm{mM}$ 4-PDS, $1 \mathrm{mM}$ EDTA, and $8 \mathrm{M}$ guanidine hydrochloride in a $50 \mathrm{mM}$ sodium phosphate buffer at $\mathrm{pH} 7.5$ (final volume of $5 \mathrm{~mL}$ ) [39]. After $1 \mathrm{~h}$, the liberation of 4-thiopyridone as a result of thiol-disulfide exchange was measured at $324 \mathrm{~nm}$ against the supernatant control with the same composition but using blocked CNBr-Sepharose ${ }^{\circledR}$ (treatment with $2 \mathrm{M}$ ethanolamine hydrochloride at $\mathrm{pH}$ 8.0) instead of the lipase derivatives. The calibration curve was made with L-cysteine (From $10 \mu \mathrm{M}$ to $100 \mu \mathrm{M}$ ) in the control medium.

\subsection{Incubation of $\mathrm{CNBr}$ Derivatives in Oxidizing/Reducing Conditions}

\subsubsection{Oxidizing Conditions}

Conditions to promote disulfide bond formation [36,38] were set when $5 \mathrm{~g}$ of $\mathrm{CNBr}$ derivatives of lipases (made with $5 \mathrm{IU} / \mathrm{g}$ or $6600 \mathrm{IU} / \mathrm{g}$ ) were suspended at $30^{\circ} \mathrm{C}$ in $50 \mathrm{mM}$ sodium phosphate buffer at pH 7.5 containing glutathione redox pair $\left(10 \mathrm{mM}\right.$ oxidized/1 mM reduced) or $\mathrm{Cu}^{2+}$ at $20 \mu \mathrm{M}$ (or $200 \mu \mathrm{M}$ concentration), and $0.1 \%$ Triton X-100 (w/v) in the presence or absence of guanidine hydrochloride $8 \mathrm{M}$ to a final volume of $50 \mathrm{~mL}$ [39]. Experiments were carried out from one day to one week when needed. Next, $\mathrm{CNBr}$ derivatives were filtered and washed thoughtfully with $1 \mathrm{mM}$ EDTA/25 mM sodium phosphate buffer at $\mathrm{pH} 7.0$, then with $25 \mathrm{mM}$ sodium phosphate buffer at $\mathrm{pH} 7.0$ and used for enzymatic assays [39].

\subsubsection{Reducing Conditions}

Five grams of $\mathrm{CNBr}$ derivatives of the enzymes (whether treated or not under oxidizing conditions) ( $5 \mathrm{IU} / \mathrm{g}$ or $6600 \mathrm{IU} / \mathrm{g}$ ) were suspended at $30^{\circ} \mathrm{C}$ in $50 \mathrm{mM}$ sodium phosphate buffer at $\mathrm{pH} 7.5$ containing glutathione redox pair ( $1 \mathrm{mM}$ oxidized/ $10 \mathrm{mM}$ reduced) or $25 \mathrm{mM}$ DTT and $0.1 \%$ Triton X-100 (w/v) in the presence or absence of guanidine hydrochloride $8 \mathrm{M}$ to a final volume of $50 \mathrm{~mL}$. Experiments were carried out from one day to one week when needed. After that, derivatives were washed as described above and immediately used for the enzymatic assay [39]. 


\subsection{Derivative Thermal Stability}

The CNBr BTL2 derivatives were incubated over time in $25 \mathrm{mM}$ sodium phosphate at $75{ }^{\circ} \mathrm{C}$ and $\mathrm{pH}$ 7.0. Samples were withdrawn periodically using a pipet with a cut-tip and under vigorous stirring to have a homogeneous biocatalyst suspension [48]. The activity was measured using the $p$-NPB assay described above.

\subsection{Transformation of Natural Triglycerides}

The sardine oil hydrolysis and the ethanolysis of palm olein with ethanol catalyzed by BTL2 and ccBTL2 CNBr-Sepharose ${ }^{\circledR}$ derivatives with $6600 \mathrm{IU} / \mathrm{g}$ was carried out as described previously $[43,44]$ with the following changes: ethanol $96 \%$ and temperature at $25^{\circ} \mathrm{C}$. All the experiments were carried out by triplicate and the standard error was under $5 \%$ unless stated otherwise.

\subsection{Targeted Molecular Dynamics}

Targeted molecular dynamics (TMD) was applied to understand the conformational changes of the transition of BTL2 from the closed to the open conformation. The information generated by TMD was then used in the analysis and calculation of the most likely conformation adopted by ccBTL2 once the cysteine mutations were included and the disulfide bond formed. The closed conformation of BTL2 was generated by homology modeling using as template the thermostable bacterial lipase L1 from Bacillus stearothermophilus [46] (PDB code: 1JI3), which, like BTL2, also belongs to the I.5 family of lipases. The open conformation of BTL2 was previously solved in complex with Triton X-100 molecules within its active site [7] (PDB code: 2W22). Three trajectories were generated using different parameters (Supplementary material, Section 1). Distances between A191 and F206 were monitored leading to intermediate conformations where the formation of disulfide bond was possible after including the cysteine mutations in both residues to create $c$ BTLL2. The resulting structures of $c c$ BTL2 with the formed disulfide bond were similar but not identical to the open conformation observed in the crystallographic structure of BTL2 (Figure 4a). Classical MD simulations were also performed in BTL2 (closed and open conformation) and ccBTL2 during $200 \mathrm{~ns}$ for further RMSD studies and pocket stability (Supplementary Material, Section 1).

\section{Conclusions}

In order to increase the activity of the Geobacillus thermocatenulatus lipase 2 (BTL2) we hypothesized that the rational insertion of two cysteine residues in specific positions (of the main lid and core of the protein) would allow us to conditionally control the level of aperture of the enzyme. The aperture is naturally controlled by a double lid restructuration to transition from a closed (inactive) state to their open and enzymatically active conformation. This conditional control, which depends on the redox conditions, would facilitate the entrance and hydrolysis of the substrate by keeping the enzyme in an active conformation. By means of a structurally-based rational design, we created the quadruple mutant ccBTL2 (A191C, F206C, C64S, and C295S), which proved effective to increase the esterase activity by 3.5 -fold in the presence of $0.1 \%$ Triton X-100 (2336 IU mg-1 $)$ and up to 6.0-fold increment with $0.01 \% \mathrm{CTAB}\left(778 \mathrm{IU} \mathrm{mg}^{-1}\right.$ ) both in the presence of oxidizing sulfhydryl agents when compared to the wild type enzyme BTL2. The insertion of this disulfide bond did not affect the specific activity, and most importantly, neither the stability of the enzyme nor the delicate transition between conformations (open to closed). In fact, $c c$ BTL2 resulted in a redox-tunable enzyme that supported several oxidation-reduction cycles that the wild type BTL2 (even in the presence of detergents) did not. All of our experimental data unequivocally indicated that the oxidized form of $c c$ BTL2, which carries the engineered disulfide bond C191-C206, was already established during extraction and/or purification of the enzyme. TMD simulations suggested a stable conformation for ccBTL2 once the engineered disulfide bond was formed. As we predicted, this conformation was structurally similar to the crystallographic open conformation previously observed, but having an active site with 
bigger volumetric capacity for both of the grooves that stabilize the acyl chains of the substrates. To our knowledge, this is the first report of a lipase engineered with a disulfide bond in the lid that effectively increases its activity [15], without compromising any other of the industrially relevant features including thermostability or tolerance to alkaline pHs that are shared by the I.5 family of lipases to which BTL2 does belong.

Supplementary Materials: Supplementary materials can be found at http://www.mdpi.com/1422-0067/20/21/ 5245/s1. 1. Molecular dynamic methods; Figure S1: Residues in BTL2 that were modified to obtain the quadruple mutant $c c$ BTL2. Figure S2: SDS-PAGE electrophoresis of BTL2 and $c c$ BTL2 lipases; Figure S3: Hydrolysis of $p$-NP esters of different acyl chain length with immobilized BTL2 and ccBTL2 with different redox pretreatments; Figure S4: Reference volumes used to monitor the variation between the crystallographic structures of BTL2 and the $c$ BTL2 model.

Author Contributions: Conceptualization C.A.G, J.M.G., J.A.H., and C.C.-L.; Methodology and formal analysis, C.A.G., C.C.-L., J.M.G., J.K., and B.D.G.; Investigation, C.A.G., C.C.-L., J.K., and B.D.G.; Writing-original draft preparation C.A.G. and C.C.-L.; Writing-review and editing, C.A.G., C.C.-L., J.M.G., J.A.H., J.K., and B.D.G.; Funding acquisition, J.M.G. and C.A.G.

Funding: Financial and logistic support from Colombian Universidad del Valle and COLCIENCIAS (CI 71083-Grant 745-2016-Project 110671250425), Spanish CICYT project BIO-2005-6018576, BFU2017-90030-P, and BFU2011-25326, B. Di G. In addition, thanks to the Spanish MINECO for a FPU fellowship.

Acknowledgments: Authors greatly acknowledge: Claudia Ortiz for the manuscript proofreading and suggestions and also José Isaza and M.Sc. Jessica Medina for their technical advice for ethyl esters quantification.

Conflicts of Interest: The authors declare no conflict of interest.

\section{Abbreviations}

$\begin{array}{ll}\text { BTL2 } & \text { Wild type Geobacillus thermocatenulatus lipase } 2 \\ \text { øBTL2 } & \text { BTL2 mutant lacking native cysteine residues (C64S, C295S BTL2) } \\ \text { ccBTL2 } & \text { A191C, F206C, C64S, C295S BTL2 (engineered mutant) } \\ \text { CNBr } & \text { Cyanogen bromide Sepharose }{ }^{\circledR} \text { support } \\ \text { CTAB } & \text { hexadecyltrimethylammonium bromide } \\ 4-P D S & 4,4^{\prime} \text {-dipyridyldisulfide } \\ \text { p-NPB } & \text { p-nitrophenyl butyrate } \\ \text { p-NP } & \text { p-nitrophenyl ester } \\ \text { DTT } & \text { Dithiothreitol } \\ \text { GSH } & \text { Glutathione (reduced form) } \\ \text { GSSG } & \text { Glutathione (oxidized form) } \\ \text { PUFAs } & \text { Polyunsaturated fatty acids } \\ \text { EPA } & \text { Eicosapentaenoic acid } \\ \text { DHA } & \text { Docosahexaenoic acid } \\ \text { TMD } & \text { Targeted Molecular Dynamics }\end{array}$

\section{References}

1. Gurung, N.; Ray, S.; Bose, S.; Rai, V. A Broader View: Microbial Enzymes and Their Relevance in Industries, Medicine, and Beyond. Available online: https:/www.hindawi.com/journals/bmri/2013/329121/ (accessed on 5 June 2019).

2. Dwivedee, B.P.; Soni, S.; Sharma, M.; Bhaumik, J.; Laha, J.K.; Banerjee, U.C. Promiscuity of Lipase-Catalyzed Reactions for Organic Synthesis: A Recent Update. ChemistrySelect 2018, 3, 2441-2466. [CrossRef]

3. Singh, A.K.; Mukhopadhyay, M. Overview of Fungal Lipase: A Review. Appl. Biochem. Biotechnol. 2012, 166, 486-520. [CrossRef] [PubMed]

4. Galante, Y.M.; Formantici, C. Enzyme Applications in Detergency and in Manufacturing Industries. Curr. Org. Chem. 2003, 7, 1399-1422. [CrossRef]

5. Niyonzima, F.N.; More, S.S. Microbial detergent compatible lipases. J. Sci. Ind. Res. 2015, 74, 105-113.

6. Verger, R. 'Interfacial activation' of lipases: Facts and artifacts. Trends Biotechnol. 1997, 15, 32-38. [CrossRef]

7. Carrasco-López, C. Activation of bacterial thermo alkalophilic lipases is spurred by dramatic structural rearrangements. J. Biolog. Chem. 2009, 284, 4365-4372. [CrossRef] 
8. Khan, F.I.; Lan, D.; Durrani, R.; Huan, W.; Zhao, Z.; Wang, Y. The Lid Domain in Lipases: Structural and Functional Determinant of Enzymatic Properties. Front. Bioeng. Biotechnol. 2017, 5, 16. [CrossRef]

9. Cowan, D.A.; Fernandez-Lafuente, R. Enhancing the functional properties of thermophilic enzymes by chemical modification and immobilization. Enzym. Microb. Technol. 2011, 49, 326-346. [CrossRef]

10. Godoy, C.A.; Romero, O.; de las Rivas, B.; Mateo, C.; Fernandez-Lorente, G.; Guisan, J.M.; Palomo, J.M. Changes on enantioselectivity of a genetically modified thermophilic lipase by site-directed oriented immobilization. J. Mol. Catal. B Enzym. 2013, 87, 121-127. [CrossRef]

11. Gao, B.; Xu, T.; Lin, J.; Zhang, L.; Su, E.; Jiang, Z.; Wei, D. Improving the catalytic activity of lipase LipK107 from Proteus sp. by site-directed mutagenesis in the lid domain based on computer simulation. J. Mol. Catal. B Enzym. 2011, 68, 286-291. [CrossRef]

12. Quilles, J.C.J.; Brito, R.R.; Borges, J.P.; Aragon, C.C.; Fernandez-Lorente, G.; Bocchini-Martins, D.A.; Gomes, E.; da Silva, R.; Boscolo, M.; Guisan, J.M. Modulation of the activity and selectivity of the immobilized lipases by surfactants and solvents. Biochem. Eng. J. 2015, 93, 274-280. [CrossRef]

13. López-Gallego, F.; Abian, O.; Guisán, J.M. Altering the interfacial activation mechanism of a lipase by solid-phase selective chemical modification. Biochemistry 2012, 51, 7028-7036. [CrossRef] [PubMed]

14. Han, Z.; Han, S.; Zheng, S.; Lin, Y. Enhancing thermostability of a Rhizomucor miehei lipase by engineering a disulfide bond and displaying on the yeast cell surface. Appl. Microbiol. Biotechnol. 2009, 85, 117-126. [CrossRef] [PubMed]

15. Yu, X.-W.; Tan, N.-J.; Xiao, R.; Xu, Y. Engineering a Disulfide Bond in the Lid Hinge Region of Rhizopus chinensis Lipase: Increased Thermostability and Altered Acyl Chain Length Specificity. PLoS ONE 2012, 7, e46388. [CrossRef] [PubMed]

16. Li, L.; Zhang, S.; Wu, W.; Guan, W.; Deng, Z.; Qiao, H. Enhancing thermostability of Yarrowia lipolytica lipase 2 through engineering multiple disulfide bonds and mitigating reduced lipase production associated with disulfide bonds. Enzym. Microb. Technol. 2019, 126, 41-49. [CrossRef] [PubMed]

17. Craig, D.B.; Dombkowski, A.A. Disulfide by Design 2.0: A web-based tool for disulfide engineering in proteins. BMC Bioinform. 2013, 14, 346. [CrossRef] [PubMed]

18. Schmidt-Dannert, C.; Rúa, M.L.; Wahl, S.; Schmid, R.D. Bacillus thermocatenulatus lipase: A thermoalkalophilic lipase with interesting properties. Biochem. Soc. Trans. 1997, 25, 178-182. [CrossRef] [PubMed]

19. Godoy, C.A. Enhanced activity of an immobilized lipase promoted by site-directed chemical modification with polymers. Process Biochem. 2010, 45, 534-541. [CrossRef]

20. Godoy, C.A.; Fernández-Lorente, G.; de las Rivas, B.; Filice, M.; Guisan, J.M.; Palomo, J.M. Medium engineering on modified Geobacillus thermocatenulatus lipase to prepare highly active catalysts. J. Mol. Catal. B Enzym. 2011, 70, 144-148. [CrossRef]

21. Khaleghinejad, S.H.; Motalleb, G.; Karkhane, A.A.; Aminzadeh, S.; Yakhchali, B. Study the effect of F17S mutation on the chimeric Bacillus thermocatenulatus lipase. J. Genet. Eng. Biotechnol. 2016, 14, 83-89. [CrossRef]

22. Tang, T.; Yuan, C.; Hwang, H.-T.; Zhao, X.; Ramkrishna, D.; Liu, D.; Varma, A. Engineering surface hydrophobicity improves activity of Bacillus thermocatenulatus lipase 2 enzyme. Biotechnol. J. 2015, 10, 1762-1769. [CrossRef] [PubMed]

23. Romero, O.; de las Rivas, B.; Lopez-Tejedor, D.; Palomo, J.M. Effect of Site-Specific Peptide-Tag Labeling on the Biocatalytic Properties of Thermoalkalophilic Lipase from Geobacillus thermocatenulatus. ChemBioChem 2018, 19, 369-378. [CrossRef] [PubMed]

24. Karkhane, A.A. The effect of substitution of Phe181 and Phe182 with Ala on activity, substrate specificity and stabilization of substrate at the active site of Bacillus thermocatenulatus lipase. J. Mol. Catal. B Enzym. 2009, 61, 162. [CrossRef]

25. Tyndall, J.D.A. Crystal structure of a thermostable lipase from bacillus stearothermophilus P1. J. Mol. Biol. 2002, 323, 859-869. [CrossRef]

26. Rua, M.L.; Atomi, H.; Schmidt-Dannert, C.; Schmid, R.D. High-level expression of the thermoalkalophilic lipase from Bacillus thermocatenulatus in Escherichia coli. Appl. Microbiol. Biotechnol. 1998, 49, 405-410. [PubMed] 
27. Godoy, C.A.; de las Rivas, B.; Grazú, V.; Montes, T.; Guisán, J.M.; López-Gallego, F. Glyoxyl-disulfide agarose: A tailor-made support for site-directed rigidification of proteins. Biomacromolecules 2011, 12, 1800-1809. [CrossRef]

28. Palomo, J.M.; Fuentes, M.; Fernández-Lorente, G.; Mateo, C.; Guisan, J.M.; Fernández-Lafuente, R. General Trend of Lipase to Self-Assemble Giving Bimolecular Aggregates Greatly Modifies the Enzyme Functionality. Biomacromolecules 2003, 4, 1-6. [CrossRef] [PubMed]

29. Schlieben, N.H. Expression, purification, and aggregation studies of his-tagged thermoalkalophilic lipase from bacillus thermocatenulatus. Protein Expr. Purif. 2004, 34, 103-110. [CrossRef]

30. Timucin, E.; Sezerman, O.U. Zinc Modulates Self-Assembly of Bacillus thermocatenulatus Lipase. Biochemistry 2015, 54, 3901-3910. [CrossRef]

31. Willems, N.; Lelimousin, M.; Skjold-Jørgensen, J.; Svendsen, A.; Sansom, M.S.P. The effect of mutations in the lid region of Thermomyces lanuginosus lipase on interactions with triglyceride surfaces: A multi-scale simulation study. Chem. Phys. Lipids 2018, 211, 4-15. [CrossRef]

32. Lambert, C.; Léonard, N.; Bolle, X.D.; Depiereux, E. ESyPred3D: Prediction of proteins 3D structures. Bioinformatics 2002, 18, 1250-1256. [CrossRef]

33. Winther, J.R.; Thorpe, C. Quantification of thiols and disulfides. Biochim. Biophys. Acta (BBA) Gen. Subj. 2014, 1840, 838-846. [CrossRef]

34. Calce, E.; Vitale, R.M.; Scaloni, A.; Amodeo, P.; De Luca, S. Air oxidation method employed for the disulfide bond formation of natural and synthetic peptides. Amino Acids 2015, 47, 1507-1515. [CrossRef]

35. Meehan, B.M.; Landeta, C.; Boyd, D.; Beckwith, J. The Disulfide Bond Formation Pathway Is Essential for Anaerobic Growth of Escherichia coli. J. Bacteriol. 2017, 199, e00120-17. [CrossRef]

36. Karlsson, M. Denaturant-assisted formation of a stabilizing disulfide bridge from engineered cysteines in nonideal conformations. Biochemistry 2005, 44, 3487-3493. [CrossRef]

37. Kim, H. Gene cloning and characterization of thermostable lipase from bacillus stearothermophilus L1. Biosci. Biotechnol. Biochem. 1998, 62, 66-71. [CrossRef]

38. Muhammad, G.; Croguennec, T.; Julien, J.; Michel, P.; Saïd, B. Copper modulates the heat-induced sulfhydryl/disulfide interchange reactions of $\beta$-Lactoglobulin. Food Chem. 2009, 116, 884-891. [CrossRef]

39. Godoy, C.A.; de las Rivas, B.; Bezbradica, D.; Bolivar, J.M.; López-Gallego, F.; Fernandez-Lorente, G.; Guisan, J.M. Reactivation of a thermostable lipase by solid phase unfolding/refolding: Effect of cysteine residues on refolding efficiency. Enzym. Microb. Technol. 2011, 49, 388-394. [CrossRef]

40. Salameh, M.A.; Wiegel, J. Effects of Detergents on Activity, Thermostability and Aggregation of Two Alkalithermophilic Lipases from Thermosyntropha lipolytica. Open Biochem. J. 2010, 4, 22-28. [CrossRef]

41. Fernandez-Lorente, G. Improved catalytic properties of immobilized lipases by the presence of very low concentrations of detergents in the reaction medium. J. Mol. Catal. B Enzym. 2007, 10, 385-393. [CrossRef]

42. Fernández-Lorente, G.; Pizarro, C.; López-Vela, D.; Betancor, L.; Carrascosa, A.V.; Pessela, B.; Guisan, J.M. Hydrolysis of Fish Oil by Lipases Immobilized Inside Porous Supports. J. Am. Oil. Chem. Soc. 2011, 88, 819-826. [CrossRef]

43. Godoy, C.A. New Strategy for the Immobilization of Lipases on Glyoxyl-Agarose Supports: Production of Robust Biocatalysts for Natural Oil Transformation. Int. J. Mol. Sci. 2017, 18, 2130. [CrossRef]

44. Toro, E.C.; Rodríguez, D.F.; Morales, N.; García, L.M.; Godoy, C.A. Novel Combi-lipase Systems for Fatty Acid Ethyl Esters Production. Catalysts 2019, 9, 546. [CrossRef]

45. Benkert, P.; Tosatto, S.C.E.; Schomburg, D. QMEAN: A comprehensive scoring function for model quality assessment. Proteins 2008, 71, 261-277. [CrossRef]

46. Jeong, S. Novel zinc-binding center and a temperature switch in the bacillus stearothermophilus L1 lipase. J. Biolog. Chem. 2002, 277, 17041-17047. [CrossRef]

47. Schlitter, J.; Engels, M.; Krüger, P. Targeted molecular dynamics: A new approach for searching pathways of conformational transitions. J. Mol. Graph. 1994, 12, 84-89. [CrossRef]

48. Fernandez-Lorente, G. Solid-Phase Chemical Amination of a Lipase from Bacillus thermocatenulatus To Improve Its Stabilization via Covalent Immobilization on Highly Activated Glyoxyl-Agarose. Biomacromolecules 2008, 9, 2553-2561. [CrossRef] 
49. Godoy, C.A.; de las Rivas, B.; Guisán, J.M. Site-directing an intense multipoint covalent attachment (MCA) of mutants of the Geobacillus thermocatenulatus lipase 2 (BTL2): Genetic and chemical amination plus immobilization on a tailor-made support. Process Biochem. 2014, 49, 1324-1331. [CrossRef]

50. Riener, C.; Kada, G.; Gruber, H. Quick measurement of protein sulfhydryls with Ellman's reagent and with 4,4'-dithiodipyridine. Anal. Bioanal. Chem. 2002, 373, 266-276. [CrossRef]

(C) 2019 by the authors. Licensee MDPI, Basel, Switzerland. This article is an open access article distributed under the terms and conditions of the Creative Commons Attribution (CC BY) license (http://creativecommons.org/licenses/by/4.0/). 